\title{
BRPKM
}

Buletin Riset Psikologi dan Kesehatan Mental

http://e-journal.unair.ac.id/index.php/BRPKM

e-ISSN: 2776-1851

ARTIKEL PENELITIAN

\section{Peranan Pondasi Moral dalam Menjelaskan Seksisme}

\author{
RIEZKY PUTRA SANTOSO \& RIZQY AMELIA ZEIN* \\ Fakultas Psikologi Universitas Airlangga
}

\begin{abstract}
ABSTRAK
Penelitian ini bertujuan untuk mengetahui peranan pondasi care/harm, fairness/cheating, authority/subversion, dan purity/sanctity dalam teori pondasi moral untuk menjelaskan hostile dan benevolent sexism. Pondasi moral didefinisikan sebagai teori untuk memahami moralitas berdasarkan kelima pondasi dasar dan seksisme ambivalen didefinisikan sebagai sikap seksisme yang memiliki dua wajah yang berbeda, hostile dan benevolent sexism. Metode penelitian yang digunakan adalah metode survei dengan kuesioner online kepada partisipan dengan kriteria yang telah ditentukan. Alat ukur yang digunakan adalah moral foundation questionnaires dan ambivalent sexism inventory. Analisis data dilakukan menggunakan analisis regresi linear dengan bantuan program Jamovi. Hasil analisis data menunjukkan bahwa hanya pondasi authority/subversion dan purity/sanctity yang menjelaskan hostile sexism secara substansial, dan pondasi fairness/cheating, authority/subversion, dan purity/sanctity yang menjelaskan benevolent sexism secara substansial.
\end{abstract}

Kata kunci: benevolent sexism, hostile sexism, pondasi moral, seksisme

\section{ABSTRACT}

This study aims to determine the role of care/harm, fairness/cheating, authority/subversion and purity/sanctity foundations in moral foundation theory to explain hostile and benevolent sexism. Moral foundation is defined as a theory to understand morality based on the five basic foundations, and ambivalent sexism is defined as an attitude of sexism that has a two different face, hostile and benevolent sexism. The research method used is survey method with online questionnaires to participants with predetermined criteria. The measuring instruments used are moral foundation questionnaires and ambivalent sexism inventory. Data analysis was performed using linear regression analysis with the help of the Jamovi program. The results of data analysis show that only authority/subversion and purity/sanctity foundation substantially explains hostile sexism, and fairness/cheating, authority/subversion, and purity/sanctity foundation that explain benevolent sexism substantially.

Keywords: benevolent sexism, hostile sexism, moral foundation, sexism

Buletin Penelitian Psikologi dan Kesehatan Mental (BRPKM), 2021, Vol. 1(1), 956-964

*Alamat korespondensi: Fakultas Psikologi Universitas Airlangga, Kampus B Universitas Airlangga Jalan Airlangga 4-6 Surabaya 60286. Surel: amelia.zein@psikologi.unair.ac.id 
sehingga penggunaan, distribusi, reproduksi dalam media apapun atas artikel ini tidak dibatasi, selama sumber aslinya disitir dengan baik.

\section{P E N D A H U L U A N}

Isu mengenai seksisme belakangan ini makin marak bermuculan dalam berbagai media. Seksisme dapat didefinisikan sebagai segala sikap, tindakan, atau struktur kelembagaan yang menurunkan harga diri, membatasi, atau mendiskriminasi seseorang atau kelompok karena jenis kelamin biologis, peran gender, atau preferensi seksual (O'neil, 1981). Seksisme dapat ditujukan kepada pria, namun pada kenyataannya seksisme lebih sering terjadi terhadap wanita, dan wanita secara historis menjadi sasaran dan menderita akibat dari perilaku seksisme tersebut (Becker dkk., 2014). Seksisme tersebut menjadi justifikasi dalam mepertahankan struktur sosial yang patriarkis serta peran gender tradisional (Glick \& Fiske, 1997).

Kasus mengenai seksisme mulai banyak bermunculan. Beberapa kasus yang muncul adalah kasus pelecehan seksual yang dialami Agni, mahasiswi dari UGM yang menjadi korban pelecehan seksual saat menjalankan KKN di Maluku, dan lambatnya penganan kasus tersebut berdampak kepada kondisi psikologis Agni yang tidak stabil (Hantoro, 2019). Kasus lain yang muncul adalah komentar seksis yang disuarakan oleh komentator liga 1 sepak bola Indonesia terhadap penonton wanita, dimana komentator tersebut memberikan pernyataan yang cabul dan mengobjektifikasi supporter wanita yang ada (Setiawan, 2020). Kasus yang paling terkini mengenai seksisme adalah kecaman terhadap pertanyaan dalam tes wawasan kebangsaan yang diikuti pegawai KPK, dimana pertanyaan yang dilontarkan kepada pegawai wanita diarahkan ke hal pribadi seperti status pernikahan, bersedia untuk dipoligami atau hasrat seksual, yang dimana pertanyaan tersebut merendahkan kehormataan wanita serta tidak ada hubungannya dengan tugas sebagai pejabat negara (Liputan6.com, 2021). Kasus-kasus tersebut menunjukkan bahwa seksisme dan diskriminasi gender masih melekat dengan masyarakat Indonesia.

Banyak sekali bentuk perilaku seksisme yang muncul dalam kehidupan sehari-hari. Dalam pernikahan, wanita diharapkan untuk memenuhi peran gender mereka sebagai wanita, yaitu mengasuh keluarganya di rumah secara full-time daripada mencari pekerjaan di luar (Blackstone, 2003). Secara kultur dan tradisi, wanita cenderung menerima bahwa pria memutuskan segalanya untuk keluarga karena dianggap lebih bijak dan cerdas, dan peran wanita ada hanya untuk mengasuh, melakukan pekerjaan rumah, dan melayani suami ketika mereka pulang dan lelah setelah bekerja (Dewi, 2019).

Dalam organisasi, wanita sering terbentur dinding diskriminasi sehingga sulit mendapatkan kesempatan yang sama dengan pria untuk mencapai puncak tertinggi organisasi (glass-ceiling effect). Fenomena glass-ceiling effect mengacu kepada hambatan diskriminatif yang mencegah wanita yang terkualifikasi untuk naik ke posisi atau memiliki tanggung jawab yang lebih tinggi dalam sebuah organisasi karena seksisme atau rasisme (Babic \& Hansez, 2021). Contohnya, di pemerintah provinsi Daerah Istimewa Yogyakarta, hanya 24.3 persen wanita yang menempati posisi pimpinan instansi (Krissetyanti, 2018).

Wanita sering menjadi korban dalam berbagai kasus pelecehan serta kekerasan seksual. Seringkali wanita yang menjadi korban disalahkan (victim blaming) atas pelecehan dan/atau kekerasan seksual yang mereka alami (Poerwandari dkk., 2019). Penelitian yang dilakukan De Judicibus \& McCabe (2001) menunjukkan bahwa seksisme secara signifikan dapat memprediksi victim blaming dalam pelecehan seksual pria-ke-wanita. Individu yang seksis akan cenderung untuk menunjukkan empati kepada pelaku pria dan menolak untuk melihat perspektif korban wanita dalam kasus pelecehan seksual (Bongiorno 
dkk., 2020). Kasus pelecehan dan kekerasan seksual yang menimpa wanita kemudian berdampak pada kemarahan moral kepada korban, bukan pelaku, yaitu dengan menyalahkan korban akibat pakaian yang digunakan. Apakah sedang dalam pengaruh alkohol, atau apakah korban sendiri atau bersama orang lain ketika pelecehan atau kekerasan seksual terjadi dan tak jarang korban wanita akan diberikan label sebagai aib oleh keluarga (Poerwandari dkk., 2019).

Seksisme telah dikonseptualisasi dalam berbagai cara, namun konseptualisasi seksisme memiliki tendensi untuk merujuk kepada sikap negatif terhadap wanita. Konseptualisasi seksisme dapat dibagi menjadi dua; yaitu, seksisme tradisional dan seksisme dengan bentuk baru (Ramiro dkk., 2018). Teori mengenai seksisme yang dapat mengakomodasi dua wajah seksisme secara lebih komperhensif adalah teori Seksisme Ambivalen (Glick \& Fiske, 2001). Meskipun seksisme mengandung unsur yang devaluatif (hostile), namun bisa saja disaat yang sama, dependensi pria terhadap wanita, pengakuan akan ketergantungan mereka terhadap wanita untuk melahirkan serta mengasuh anak, mengerjakan pekerjaan rumah tangga, serta memenuhi kebutuhan seksual merupakan representasi proteksi paternal terhadap wanita sebagai kelompok yang lebih lemah namun esensial. Hal ini juga disebut sebagai benevolent sexism, yang mengimbangi (Glick \& Fiske, 2001)

Seksisme memiliki dampak yang buruk kepada wanita, namun penyebab utama dari perilaku maupun atribut yang berkontribusi pada perilaku tersebut belum diteliti secara menyeluruh (McPherson, 2019). Beberapa penelitian sebelumnya menunjukkan bahwa seksisme merupakan refleksi dari penilaian moral, dimana individu yang memiliki tingkat penilaian moral yang tinggi cenderung untuk menentang pernyataan seksis mengenai posisi wanita dalam masyarakat (Uzendoorn, 1990). Penelitian lain yang dilakukan oleh Chan \& Haslam (2019) menunjukkan bahwa pemerluasan konsep mengenai seksisme dapat dengan baik memprediksi penilaian moral terhadap korban dan pelaku perilaku seksis.

Salah satu teori moral yang dapat membantu menjelaskan mengenai seksisme adalah teori Pondasi Moral (Graham dkk., 2013). Teori Pondasi Moral mengusulkan bahwa ada beberapa sistem psikologis universal yang menjadi pondasi dari "etika intuitif" yang memberikan petunjuk bagaimana orang lain harus diperlakukan (Graham dkk., 2013). Di atas pondasi tersebut, tiap kultur membangun moralitas yang unik antar kultur yang menekankan tiap pondasi dengan tingkat yang beragam (Vecina \& Chacón, 2019). Teori ini menilai pandangan individu mengenai perilaku yang merugikan individu lainnya yang terdiri dari lima pondasi dasar (Graham dkk., 2011). Pondasi tersebut adalah: (1) care/harm, (2) fairness/cheating, (3) ingroup/loyalty, (4) authority/subversion, dan (5) purity/sanctity (Graham dkk., 2013).

Dalam penelitian yang dilakukan oleh Vecina \& Piñuela (2017), ditemukan hubungan antara teori pondasi moral dengan kedua dimensi seksisme ambivalen, dimana benevolent sexism berkorelasi positif dengan authority/subversion dan hostile sexism berkorelasi negatif dengan fairness/cheating. Kedua pondasi tersebut membantu menjelaskan kedua dimensi seksisme ambivalen, namun hanya pondasi fairness/cheating yang dapat memprediksi intensi perubahan sikap kekerasan terhadap pasangan (Vecina \& Piñuela, 2017). Penelitian lainnya yang dilakukan oleh Vecina \& Chacón (2019) memperlihatkan bahwa bahwa hampir semua partisipan studi yang telah didakwa melakukan kekerasan terhadap pasangan menunjukan penghargaan yang tinggi untuk tidak membahayakan orang lain (care/harm), memperlakukan orang lain dengan adil (fairness/cheating), dan menjalani kehidupan yang memiliki penguasaan diri yang tinggi (purity/sanctity), sehingga mereka menunjukan lebih banyak benevolent sexism dibandingkan hostile sexism.

Berdasarkan permasalahan penelitian yang telah dijabarkan, peneliti memutuskan untuk menginvestigasi lebih lanjut; apakah hostile dan benevolent sexism dalam teori Seksisme Ambivalen 
dapat dijelaskan oleh dimensi care/harm, fairness/cheating, authority/subversion, dan purity/sanctity dalam teori Pondasi Moral.

\section{E T O D E}

\section{Desain Penelitian}

Pendekatan yang digunakan dalam penelitian adalah teknik kuantitatif, dengan desain penelitian survei cross-sectional (Neuman, 2014). Metode ini dipilih untuk mengetahui apakah pondasi moral yang dianut memiliki korelasi terhadap pandangan seksisme ambivalen. Dalam studi kuantitatif, penelitian dilakukan dengan penyebaran kuesioner secara online melalui google form yang berisi skala pondasi moral dan seksisme ambivalen. Kriteria partisipan dalam penelitian ini adalah : (1) WNI, (2) Berusia 1865 tahun, (3) Beridentitas gender cis pria maupun wanita. Peneliti membuat dua model dalam penelitian; pertama, dimana hostile sexism merupakan fungsi dari care/harm, fairness/cheating, authority/subversion, dan purity/sanctity, sedangkan model kedua adalah benevolent sexism yang merupakan fungsi linier dari care/harm, fairness/cheating, authority/subversion, dan purity/sanctity.

\section{Partisipan}

Penelitian ini menggunakan metode non-probability sampling dengan teknik sampling purposive sampling. Jumlah sampel partisipan penelitian diambil berdasarkan perhitungan sampel yang dilakukan menggunakan aplikasi GPower dengan teknik a priori power analysis (Faul dkk., 2009). Untuk mendeteksi ukuran efek minimal yang ingin diteliti (smallest effect size of interest) dalam satuan Cohen's $f^{2}$ sebesar 0.07, maka penelitian memerlukan total sampel minimal 271 partisipan. Jumlah partisipan dalam penelitian berjumal 299 orang $(\mathrm{N}=299)$ yang telah memenuhi kriteria responden. Partisipan terdiri dari responden dengan jenis kelamin wanita 55,2\% ( $\mathrm{N}=165)$ dan responden dengan jenis kelamin pria $44.8 \%(\mathrm{~N}=134)$ dengan rentang usia 18-37 tahun $\left(M_{\text {usia }}=22,9\right.$ tahun, $\left.S D_{\text {usia }}=3,67\right)$. Persebaran domisili responden dengan ketiga tertinggi adalah Jawa Timur dengan $24.7 \%(\mathrm{~N}=74)$, Jawa Barat dengan 17.7\% ( $\mathrm{N}=53)$, dan Jawa Tengah dengan 9.7\% ( $\mathrm{N}=29)$. Partisipan diberikan informed consent sebelum memulai penelitian ini.

\section{Pengukuran}

Pengukuran pondasi moral dalam penelitian ini menggunakan moral foundation questionnaires (MFQ) yang disusun oleh Graham dkk. (2011) diterjemahkan oleh peneliti. Skala terdiri dari 30 aitem yang mengukur kelima pondasi moral dengan 6 kategori jawaban $(1=$ "tidak relevan sama sekali/sangat tidak setuju",6="sangat relevan/sangat setuju"). Dalam penelitian ini hanya mengukur empat dari lima pondasi moral saja, yaitu care/harm, fairness/cheating, authority/subversion, dan purity/sanctity. Seksisme diukur menggunakan Ambivalent Sexism Inventory yang disusun oleh Glick \& Fiske (1996) dan diterjemahkan oleh peneliti. Skala terdiri dari 22 aitem yang terdiri dari 11 aitem hostile sexism dan 11 aitem benevolent sexism dengan 6 kategori jawaban ( $1=$ "sangat tidak setuju",6="sangat setuju")

Validitas yang digunakan yaitu validitas internal dengan validitas konten. Validitas konten dilakukan dengan bantuan review professional dan awam menggunakan Content Validity Index (CVI). Penghitungan reliabilitas menggunakan McDonald's omega untuk keempat subskala MFQ dan kedua subskala ASI. Hasil Analisa reliabilitas menunjukkan koefisien reliabilitas untuk subskala MFQ yaitu care/harm, fairness/cheating, authority/subversion, dan purity sanctity adalah .50, .57, .45, .67 dan untuk subskala ASI yaitu hostile sexism dan benevolent sexism adalah .83 dan .74. 
Pemerolehan skor dilakukan dengan dijumlah. Uji asumsi dilakukan adalah normalitas residual, heterokedastisitas, multikolinearitas. Uji normalitas residual dilakukan menggunakan $Q-Q$ Plot dan hasil uji untuk kedua model penelitian cenderung seragam. Uji heterokedastisitas untuk kedua model menunjukkan sebaran varians yang sama. Uji multikolinearitas menunjukkan bahwa variabel yang diteliti tidak menunjukkan multikolinearitas (care/harm, toleransi = .591, VIF = 1.69; fairness/cheating, toleransi $=.693, \mathrm{VIF}=1.44 ;$ authority/subversion, toleransi $=.563, \mathrm{VIF}=1.78 ;$ purity $/$ sancity, toleransi $=$ $.500, \mathrm{VIF}=2.00$ )

\section{Analisis Data}

Pengujian hipotesis dilakukan menggunakan uji regresi linear. Perangkat lunak yang digunakan untuk melakukan uji hipotesis adalah program Jamovi versi 1.6.15 solid.

\section{HAS I L P EN EL I T I A N}

Uji regresi pada model pertama menunjukan bahwa model regresi cocok dalam menggambarkan data $\left(F(4,294)=8,778 ; p<0,001, \mathrm{R}^{2}=0,107\right)$, dimana 10,7 persen varians keseluruhan variabel independen dapat menjelaskan variabel dependen, yaitu hostile sexism. Pondasi care/harm (B=-0,348; 95\% CI [$0,631 ;-0,066] ; S E=0,143 ; t=-2.42 ; p=0,016)$ berkorelasi moderat dan negatif, dan pondasi authority/subversion $(B=0,582 ; 95 \% C I[0,309 ; 0,855] ; S E=0,139 ; t=4.19 ; p=<0,001)$ berkorelasi moderat dan positif dalam menjelaskan hostile sexism. Pondasi fairness/cheating $(B=-0,076 ; 95 \% C I[-0,320$; $0,168] ; S E=0,124 ; t=-0.61 ; p=0.542)$ dan purity/sanctity $(B=0,160 ; 95 \% C I[-0,077 ; 0,398] ; S E=0,121 ; t=-$ $1.32 ; p=0.186$ ) tidak substansial dalam menjelaskan variasi hostile sexism karena korelasi yang lemah dengan hostile sexism.

Uji regresi pada model kedua menunjukan bahwa model regresi cocok dalam menggambarkan data $\left(F(4,294)=35,46 ; p<0,001, \mathrm{R}^{2}=0,325\right)$, dimana 32,5 persen varians keseluruhan variabel independen dapat menjelaskan variabel dependen, yakni benevolent sexism. Pondasi fairness/cheating $(B=-0,378$; $95 \%$ CI $[-0,631 ;-0,125] ; S E=0,127 ; t=-2.95 ; p=0.003)$ berkorelasi moderat dan negatif, pondasi authority/subversion $(B=0,326 ; 95 \% C I[0,046 ; 0,608] ; S E=0,143 ; t=2.27 ; p=0.024)$ berkorelasi moderat dan positif, dan pondasi purity/sanctity $(B=0,973 ; 95 \% C I[0,727 ; 1,218] ; S E=0,125 ; t=7.79 ; p=<0.001)$ berkorelasi kuat dan positif dalam menjelaskan benevolent sexism. Pondasi care/harm $(B=-0,051 ; 95 \%$ $C I[-0,343 ; 0,241]$; $S E=0,148 ; t=-0.34 ; p=0.731)$ tidak substansial dalam menjelaskan variasi benevolent sexism karena korelasi yang lemah dengan benevolent sexism.

\section{I S K U S I}

Penelitian ini dilakukan untuk meneliti apakah pondasi care/harm, fairness/cheating, authority/subversion, dan purity/sanctity dapat menjelaskan perilaku seksisme ambivalen. Berdasarkan hasil analisis data, ditemukan bahwa hasil data mendukung sebagian hipotesis. Apabila ditinjau dari penelitian milik Vecina \& Piñuela (2017) dan Vecina \& Chacón (2019), hasil penelitian selaras dengan temuan penelitian tersebut dimana pondasi authority/subversion dan purity/sanctity memiliki hubungan yang positif terhadap benevolent sexism. Hasil ini tidak mengejutkan dikarenakan kedua pondasi tersebut berhubungan dengan motivasi kebaikan, menjaga hierarki (authority/subversion), dan kemurnian (purity/sanctity). Hubungan tersebut dapat terjadi dikarenakan pondasi authority/subversion yang menginginkan otoritas untuk menjaga ketertiban serta keadilan, dalam hal ini membantu mempertahankan penghargaan terhadap wanita dalam peran gender tradisional serta melindungi mereka (Haidt, 2012; Harper \& Harris, 2017), dan pondasi purity/sanctity, dimana adanya 
penghargaan yang lebih tinggi pada hal yang murni dan menghindari hal-hal yang tidak natural dan menjijikan, dalam hal ini pondasi tersebut melihat wanita sebagai individu yang murni dan bebas dari patogen sosial (Harper \& Harris, 2017).

Hal menarik lain yang muncul dari hasil penelitian adalah hubungan pondasi moral dengan hostile sexism, bahwa pondasi authority/subversion dan purity/sanctity pula memiliki hubungan yang positif dengan hostile sexism, dimana kedua pondasi tersebut berhubungan pula dengan ketidaktsetaraan kuasa (authority/subversion) dan kemurnian atau kesucian (purity/sanctity). Hubungan tersebut pula dapat terjadi dikarenakan pondasi authority/subversion dapat menunjukan adanya ketidaksetaraan hierarki antara pria dan wanita, dimana wanita perlu dikontrol oleh pria (Glick \& Fiske, 1997), serta pondasi purity/sanctity, dimana wanita yang sudah "terkontaminasi" akan mendapatkan citra yang lebih buruk dan dianggap menjadi patogen sosial (Harper \& Harris, 2017).

Penelitian ini tidak menemukan bukti yang berarti untuk mendukung hipotesis bahwa pondasi fairness/cheating memiliki hubungan negatif dengan hostile sexism, serta hipotesis bahwa care/harm memiliki hubungan positif dengan benevolent sexism. Tidak terbuktinya hipotesis tersebut dapat diakibatkan karena kultur Indonesia yang masih cenderung konservatif, dimana kultur konservatif tersebut pada dasarnya menginginkan pelestarian serta mempromosikan institusi sosial tradisional (Heywood, 2017). Budaya patriarki yang masih marak dalam kehidupan sehari-hari (Rokhimah, 2015), serta nilai-nilai agama islam sebagai agama mayoritas di Indonesia yang mulai condong ke arah konservatif (Abdullah \& Osman, 2018). Nilai konservatif tersebut memiliki kepercayaan serta penilaian yang lebih pada pondasi ingroup/loyalty, authority/subversion, dan purity/sanctity (binding foundation) (Graham dkk., 2013) sehingga pondasi tersebut dapat cukup menjelaskan hostile sexism dan benevolent sexism jika dibandingkan dengan pondasi care/harm dan fairness/cheating (individualizing foundation) dalam masyarakat Indonesia. Karena itu, dapat dipahami apabila individualizing foundation (care/harm dan fairness/cheating) yang lekat akan nilai-nilai liberal belum cukup untuk memberikan penjelasan yang bermakna mengenai mengapa pandangan seksisme dianut secara umum, akibat begitu kuatnya seksisme dan diskriminasi gender melekat pada kultur masyarakat Indonesia

\section{S I M P U L A N}

Hasil penelitian menunjukan bahwa hanya pondasi authority/subversion dan purity/sanctity yang menjelaskan hostile sexism secara substansial, dan pondasi fairness/cheating, authority/subversion, dan purity/sanctity yang menjelaskan benevolent sexism secara substansial. Kurang substansialnya pondasi care/harm dalam menjelaskan kedua bentuk seksisme dan pondasi fainres/cheating dalam menjelaskan hostile sexism disebabkan karena kultur Indonesia yang cenderung mengarah konservatif sehingga kedua pondasi tersebut yang lekat akan nilai-nilai liberal kurang mampu dalam menjelaskan mengapa pandangan seksisme dianut secara umum.

Untuk penelitian selanjutnya yang membahas hal serupa, diharapkan mempertimbangkan faktor-faktor yang bersifat struktural, seperti faktor-faktor sosio-historis dan kultural dalam menyelidiki keterkaitan antara penilaian moral dengan seksisme dan diskriminasi gender. Saran lain yang dapat dilakukan dalam penelitian selanjutnya ialah berfokus kepada satu kultur yang spesifik agar dapat menggambarkan penilaian moral yang khas dalam kultur tersebut. 


\section{U C A P A N T ER I MAKASIH}

Peneliti mengucapkan terima kasih kepada dosen pembimbing yaitu Ibu Rizqy Amelia Zein S.Psi., M.Sc., yang telah membimbing peneliti selama penelitian berlangsung. Tidak lupa pula kepada partisipan yang telah bersedia untuk mengikuti penelitian ini.

\section{DEKLARASI POTENSI TERJADINYA KONFLIK KEPENTINGAN}

Riezky Putra Santoso dan Rizqy Amelia Zein tidak bekerja, menjadi konsultan, memiliki saham, atau menerima dana dari perusahaan atau organisasi manapun yang mungkin akan mengambil untung dari diterbitkannya naskah ini.

\section{PUST A KA ACUAN}

Abdullah, N., \& Osman, M. N. M. (2018). Islamisation in the Indonesian media spaces new sites for a conservative push. Journal of Religious and Political Practice, 4(3), 214-232. https://doi.org/10.1080/20566093.2018.1525894

Babic, A., \& Hansez, I. (2021). The Glass Ceiling for Women Managers: Antecedents and Consequences for Work-Family Interface and Well-Being at Work. Frontiers in Psychology, 12. https://doi.org/10.3389/fpsyg.2021.618250

Becker, J. C., Zawadzki, M. J., \& Shields, S. A. (2014). Confronting and Reducing Sexism: A Call for Research on Intervention. Journal of Social Issues, 70(4), 603-614. https://doi.org/10.1111/josi.12081

Blackstone, A. M. (2003). Gender Roles and Society. 335.

Bongiorno, R., Langbroek, C., Bain, P. G., Ting, M., \& Ryan, M. K. (2020). Why Women Are Blamed for Being Sexually Harassed: The Effects of Empathy for Female Victims and Male Perpetrators. Psychology of Women Quarterly, 44(1), 11-27. https://doi.org/10.1177/0361684319868730

Chan, J., \& Haslam, N. (2019). Broad concepts of sexism predict polarized moral judgments of victims and perpetrators. Personality and Individual Differences, 150, 109488. https://doi.org/10.1016/j.paid.2019.06.031

De Judicibus, M., \& McCabe, M. P. (2001). Blaming the Target of Sexual Harassment: Impact of Gender Role, Sexist Attitudes, and Work Role. Sex Roles, 44(7), 401-417. https://doi.org/10.1023/A:1011926027920

Dewi, D. M. (2019). The Representation of Patriarchy in Indonesian Children Folk Tales from Sumatra Island. Lingua Cultura, 13(3), 167-172. https://doi.org/10.21512/lc.v13i3.5646

Faul, F., Erdfelder, E., Buchner, A., \& Lang, A.-G. (2009). Statistical power analyses using G*Power 3.1: Tests for correlation and regression analyses. Behavior Research Methods, 41(4), 1149-1160. https://doi.org/10.3758/BRM.41.4.1149 
Glick, P., \& Fiske, S. (1996). The Ambivalent Sexism Inventory: Differentiating Hostile and Benevolent Sexism. Journal of Personality and Social Psychology, 70, 491-512. https://doi.org/10.1037/0022-3514.70.3.491

Glick, P., \& Fiske, S. (2001). An Ambivalent Alliance: Hostile and Benevolent Sexism as Complementary Justifications for Gender Inequality. The American Psychologist, 56, 109-118. https://doi.org/10.1037/0003-066X.56.2.109

Glick, P., \& Fiske, S. T. (1997). Hostile and Benevolent Sexism: Measuring Ambivalent Sexist Attitudes Toward Women. Psychology of Women Quarterly, 21(1), 119-135. https://doi.org/10.1111/j.1471-6402.1997.tb00104.x

Graham, J., Haidt, J., Koleva, S., Motyl, M., Iyer, R., Wojcik, S. P., \& Ditto, P. H. (2013). Chapter Two - Moral Foundations Theory: The Pragmatic Validity of Moral Pluralism. In P. Devine \& A. Plant (Eds.), Advances in Experimental Social Psychology (Vol. 47, pp. 55-130). Academic Press. https://doi.org/10.1016/B978-0-12-407236-7.00002-4

Graham, J., Nosek, B. A., Haidt, J., Iyer, R., Koleva, S., \& Ditto, P. H. (2011). Mapping the Moral Domain. Journal of Personality and Social Psychology, 101(2), 366-385. https://doi.org/10.1037/a0021847

Haidt, J. (2012). The Righteous Mind: Why Good People are Divided by Politics and Religion. Pantheon Books.

Hantoro, J. (2019, February 10). Kasus Agni UGM, Korban Disalahkan Hingga Depresi. Tempo. https://nasional.tempo.co/read/1174054/kasus-agni-ugm-korban-disalahkan-hingga-depresi

Harper, C. A., \& Harris, A. J. (2017). Applying moral foundations theory to understanding public views of sexual offending. Journal of Sexual Aggression, 23(2), 111-123. https://doi.org/10.1080/13552600.2016.1217086

Heywood, A. (2017). Political Ideologies: An Introduction.

Krissetyanti, E. P. L. (2018). Women's Perceptions about Glass Ceiling in their Career Development in Local Bureaucracy in Indonesia. BISNIS \& BIROKRASI: Jurnal Ilmu Administrasi Dan Organisasi, 25(1), Article 1. https://doi.org/10.20476/jbb.v25i1.9643

Liputan6.com. (2021, May 9). Komnas Perempuan: Pertanyaan Seksis di Tes Wawasan Kebangsaan KPK Tunjukan Rendahnya Perspektif Gender. liputan6.com. https://www.liputan6.com/news/read/4554192/komnas-perempuan-pertanyaan-seksis-dites-wawasan-kebangsaan-kpk-tunjukan-rendahnya-perspektif-gender

McPherson, R. (2019). The Influence of Spirituality, Moral Reasoning, and Personality Factors on Misogyny. The Pegasus Review: UCF Undergraduate Research Journal, 10(2). https://stars.library.ucf.edu/urj/vol10/iss2/5

Neuman, W. L. (2014). Social Research Methods: Qualitative and Quantitative Approaches. Pearson Education Limited. 
O'neil, J. M. (1981). Patterns of Gender Role Conflict and Strain: Sexism and Fear of Femininity in Men's Lives. The Personnel and Guidance Journal, 60(4), 203-210. https://doi.org/10.1002/j.21644918.1981.tb00282.x

Poerwandari, E. K., Utami, C. P., \& Primasari, I. (2019). Ambivalent sexism and sexual objectification of women as predictors of rape myth acceptance among male college students in Greater Jakarta. Current Psychology. https://doi.org/10.1007/s12144-019-00500-w

Ramiro, T., Ramiro, M., Bermúdez, M., \& Buela-Casal, G. (2018). Sexism in Adolescent Relationships: A Systematic Review. Psychosocial Intervention, 27, 000-000. https://doi.org/10.5093/pi2018a19

Rokhimah, S. (2015). PATRIARKHISME DAN KETIDAKADILAN GENDER / MUWAZAH: Jurnal Kajian Gender. http://e-journal.iainpekalongan.ac.id/index.php/Muwazah/article/view/440

Setiawan, R. (2020). Komentator Liga 1 Cabul dan Kurang Ajar kepada Suporter Perempuan. tirto.id. https://tirto.id/komentator-liga-1-cabul-dan-kurang-ajar-kepada-suporter-perempuan-eD3K

Uzendoorn, M. H. van. (1990). The relation of moral judgement to authoritarianism, sexism, ethnocentrism, and concern about nuclear war. Journal of Moral Education, 19(1), 38-47. https://doi.org/10.1080/0305724900190105

Vecina, M. L., \& Chacón, J. C. (2019). The Extreme Moral Diversity of Men Convicted of Violence Against Their Partners: Four Profiles Based on the Five Moral Foundations. Journal of Interpersonal Violence, 0886260519835005. https://doi.org/10.1177/0886260519835005

Vecina, M. L., \& Piñuela, R. (2017). Relationships between Ambivalent Sexism and the Five Moral Foundations in Domestic Violence: Is it a Matter of Fairness and Authority? The Journal of Psychology, 151(3), 334-344. https://doi.org/10.1080/00223980.2017.1289145 